\title{
Comparison of Minimally Invasive Tubular Surgery with Conventional Surgery in the Treatment of Thoracolumbar Metastasis
}

\author{
Yunpeng Cui (D) \\ Xuedong Shi \\ Chuan Mi \\ Bing Wang \\ Yuanxing Pan \\ Yunfei Lin
}

Department of Orthopaedics, Peking University First Hospital, Beijing, People's

Republic of China
Correspondence: Xuedong Shi Department of Orthopedic, Peking University First Hospital, No. 7 Xishiku Street, Xicheng District, Beijing, 100032, People's Republic of China Tel +86 10-83575660

Email pku_ortho@163.com
Background: This study aimed to evaluate the perioperative safety and efficacy of minimally invasive tubular surgery for patients with spinal metastasis.

Methods: A total of 161 consecutive patients with spinal metastasis between June 2017 and June 2020 were retrospectively reviewed. A total of 36 patients were included in this study, 14 patients underwent minimally invasive tubular surgery $(\mathrm{M})$, and 22 patients underwent conventional surgery (C). T-test and chi-square tests were used to evaluate demographic and perioperative data differences between the two groups.

Results: Baseline characteristics did not differ significantly between $\mathrm{M}$ and $\mathrm{C}$ groups except for the SINS $(p=0.002)$ and preoperative Alb $(p=0.026)$. There was no significant difference in operative time and complications between $\mathrm{M}$ and $\mathrm{C}$ groups $(\mathrm{p}<0.05)$. The $\mathrm{M}$ group had less mean blood loss than the $\mathrm{C}$ group $(1275$ vs $718 \mathrm{~mL}, \mathrm{p}=0.045)$. Blood transfusion was comparable between the two groups $(p<0.05)$. The mean amount and drainage time were lower than the $\mathrm{C}$ group (141 vs $873 \mathrm{~mL}, \mathrm{p}<0.001 ; 3.1$ vs 7.0 days, $\mathrm{P}<0.001$ ). The mean postoperative hospitalization of the $M$ group was 8.8 days, which was lower than the $C$ group (11.3 days, $\mathrm{p}=0.045$ ). Sub-analysis showed that for patients with hyper-vascular tumor, the $\mathrm{M}$ group had less mean amount and time of drainage compared with the $\mathrm{C}$ group $(\mathrm{p}<0.05)$; for patients with hypovascular tumor, the mean blood loss and amount of blood transfusion were also reduced in $\mathrm{M}$ group $(\mathrm{p}<0.05)$. The mean blood loss and drainage time of patients with hypo-vascular tumors were less than patients with hyper-vascular tumors in the M group $(\mathrm{p}<0.05)$.

Conclusion: In selected cases, minimally invasive tubular surgery is safe and effective for patients with spinal metastasis. Patients with hypo-vascular tumors were more suitable for this technique with less blood loss, fewer blood transfusions, minor drainage, and shorter postoperative hospitalization.

Keywords: spinal metastasis, minimally invasive tubular surgery, minimally invasive spine surgery, conventional surgery, tubular retractor, hypo-vascular tumor

\section{Background}

The number of patients with spinal metastasis has remarkably increased for many populations and extended patient survival. ${ }^{1}$ Treatment of spinal metastasis depends on the patients' global performance status, expected survival, and neurological and mechanical factors. ${ }^{2}$ Conventional surgery is useful for managing patients with spinal metastasis, such as metastatic spinal cord compression and intractable pain due to spinal instability. ${ }^{3,4}$ However, the incidence of postoperative complications is higher. ${ }^{5}$ Those patients need a relatively more extended period to recover, and the 
subsequent treatment, such as radiation, chemotherapy, or targeted drug, has to be postponed. Minimally invasive spine surgeries are characterized by minor physiological insult and fewer postoperative complications, allowing early mobilization and rapid recovery. ${ }^{6}$ These techniques, such as percutaneous pedicle screw fixation with or without mini-open, have been applied in managing symptomatic spinal metastases and achieved positive therapeutic results. $^{7-13}$

Foley KT first proposed mini-invasive transforaminal lumbar interbody fusion (Mis-TLIF) through an expandable tubular retractor. Minimally invasive tubular surgery constituted the core of this surgical technique and was widely used in treating degenerative spinal diseases. MisTLIF can achieve the same therapeutic effect in safety, pain reduction, and neurological outcome compared to conventional surgery. ${ }^{14}$ Whether this is the case for spinal metastases' surgical treatment has not yet been examined thoroughly. Studies have reported that minimally invasive tubular surgery was safe and effective for patients with spinal metastases. ${ }^{15-19}$ A clear operation field is one of the keys to achieving successful surgical results. Intraoperative tumor bleeding, especially hyper-vascular tumors, can seriously affect the clarity of the operation field. Patients with spinal metastases could have different primary tumors and blood supplies. However, there was no clear statement on the selection of patients with primary tumors of different blood supply in the previous studies. ${ }^{15-}$

19 The present study aimed to evaluate the perioperative safety and efficacy of minimally invasive tubular surgery for patients with thoracolumbar metastasis and guide surgeons to select the best candidates.

\section{Methods}

\section{Study Design and Selection Criteria}

From June 2017 to June 2020, a total of 161 consecutive patients with spinal metastasis underwent surgical treatment at our department. Surgical indications were intractable pain due to spinal instability and myelopathy/ radiculopathy caused by spinal metastasis, those not responding to conservative treatment such as radiation and chemotherapy. The surgery option was determined by multidisciplinary cooperation, composed of neuroradiologist, spinal tumor surgeons, and oncologists. In the present study, the indication for minimally invasive tubular surgery included: 1) intractable pain due to spinal instability and myelopathy/ radiculopathy caused by spinal metastasis, those not responding to conservative treatment. 2) Single-segment depression with unilateral pedicle or vertebrae involvement. The compression can be relieved by unilateral tumor resection. 3) Non-solitary metastasis. 4) Effective medical systemic therapy or local

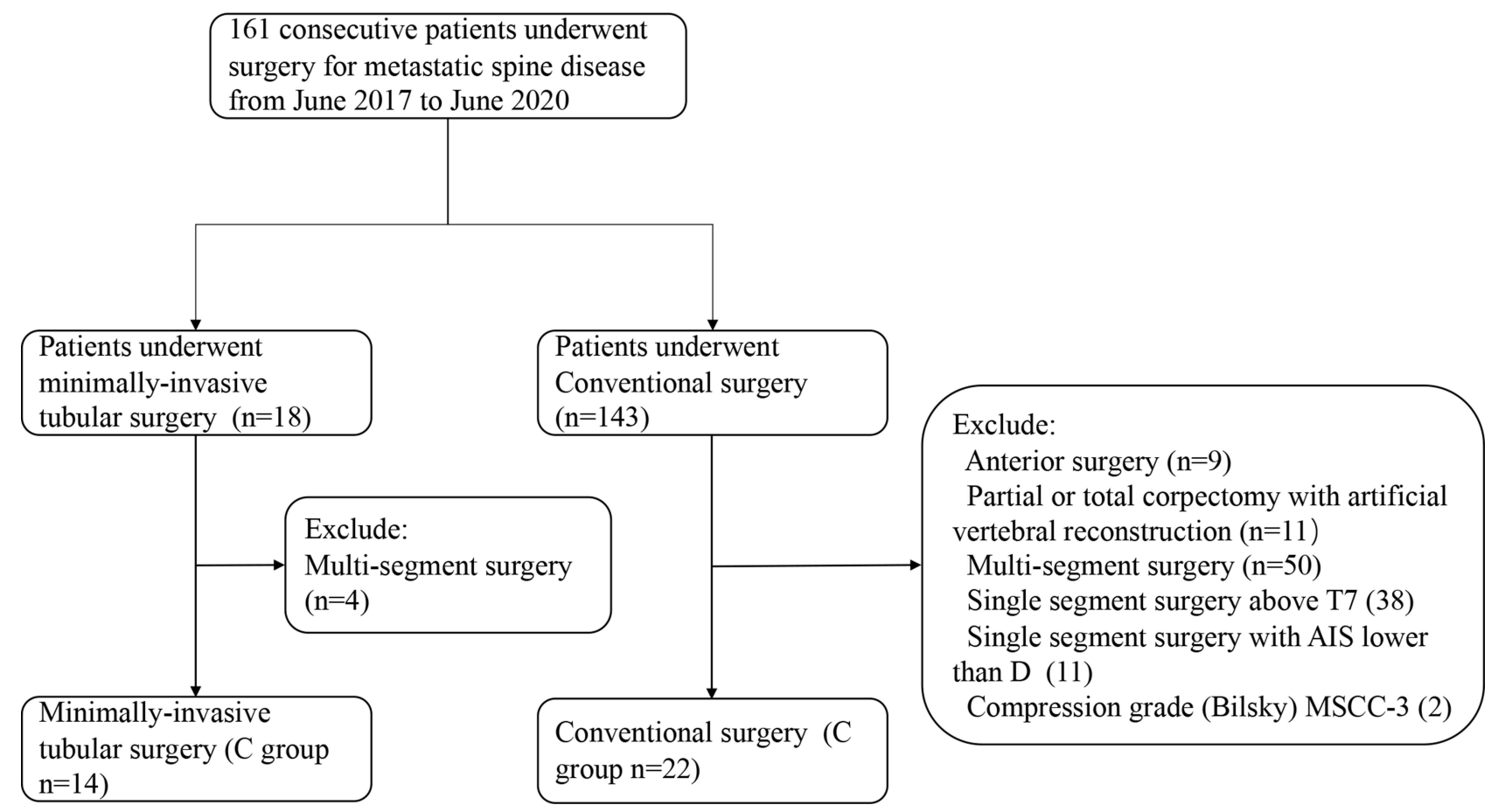

Figure I The flowchart of patient inclusion. 
radiotherapy can be implemented after an operation. These patients were systematically reviewed, and patients with the following criteria were excluded from our study: 1) anterior surgery; 2) Partial or total corpectomy with artificial vertebral reconstruction; 3) Multi-segment surgery; 4) American Spinal Injury Association Impairment Scale (AIS) lower than D; 5) Compression grade (Bilsky) was 3; 6) Spinal metastasis above T7 (We defined not to use percutaneous screws above T7); 7) local recurrence.

36 patients met the criteria and were included in this study. Patients were assigned to 2 groups according to the surgical method: minimally invasive tubular surgery ( $M$ group, $n=14)$; conventional surgery (C group, $\mathrm{n}=22$ ). The flow of patient enrolment is shown in Figure 1. All patients underwent a physical examination, X-ray, and Magnetic Resonance Imaging (MRI) or computer tomography to confirm the lesion's location. Their blood samples were taken for routine tests before surgery.

\section{Data Collection}

Patients' characteristics, including demographic information, Body Mass Index (BMI), American Society of Anesthesiologists (ASA) score, primary tumor type, location of the lesion, grade of epidural compression, Tokuhashi score, Spinal Instability Neoplastic Score (SINS) score, Karnofsky score, Eastern Cooperative Oncology Group (ECOG), Visual Analogue Scale (VAS), ambulatory status and neurological function according to AIS were carefully extracted from their electronic medical records. Metastasis from renal, liver, and thyroid tumors was assigned to hyper-vascular tumors. ${ }^{20,21}$ Perioperative data including operative time, blood loss (measure the suction loss and weigh the gauzes), preoperative arterial embolism, patients with blood transfusion and milliliter transfused, surgically related complications, a total milliliter of drainage, postoperative hospitalization, and laboratory data including hemoglobin (HGB), hematocrit (Hct) and albumin (Alb) were also extracted. Follow-up data including VAS,
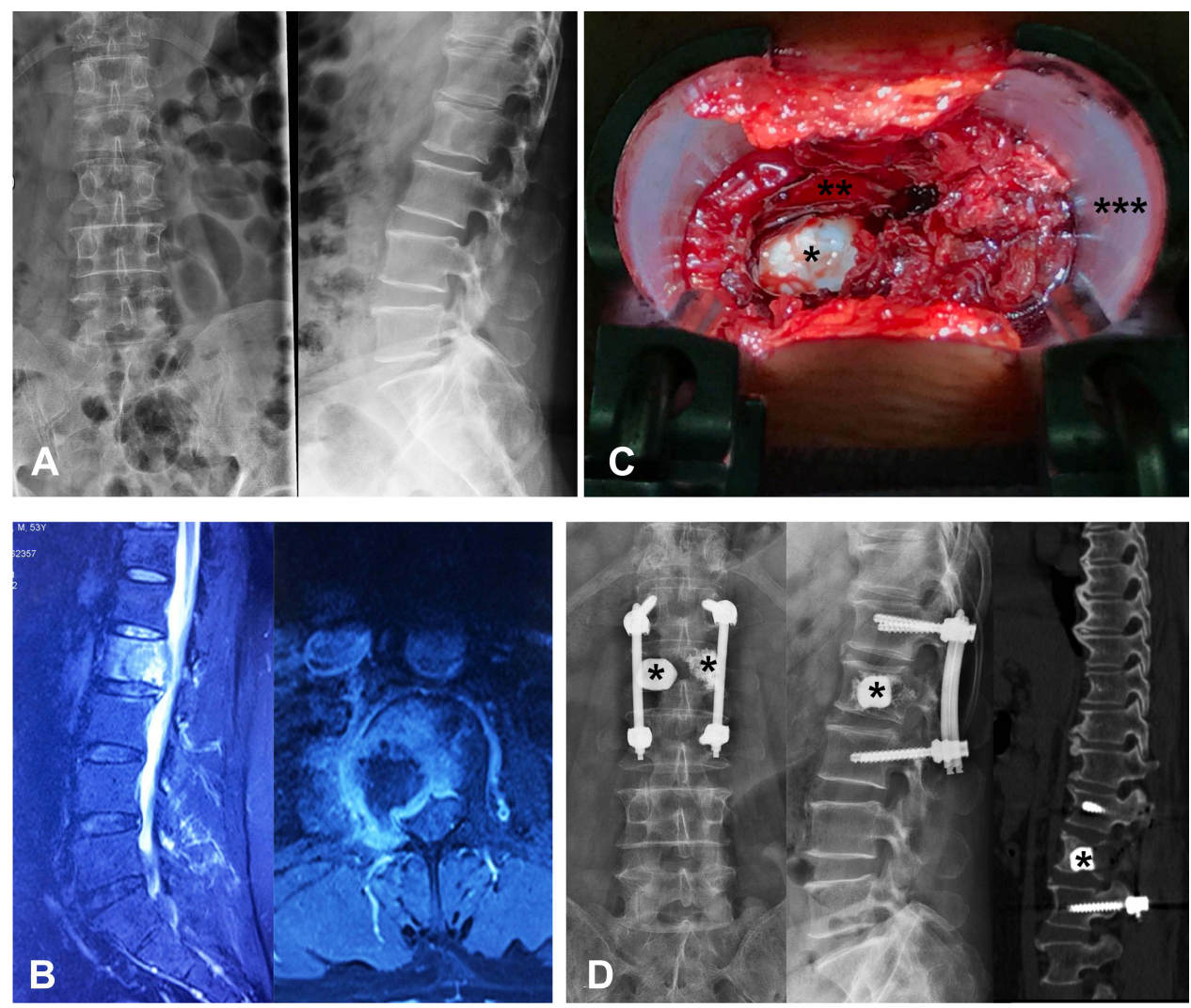

Figure 2 Illustration of minimally invasive tubular surgery. (A) Preoperative X-ray showing bone destruction of L2 vertebra. (B) Preoperative MRI showing metastatic epidural spinal cord compression due to collapsed L2 metastatic lesion. (C) minimally invasive decompression was performed through an expandable tubular retractor. (D) Postoperative X-ray, and CT scan were showing the decompression site and implants. (asterisk *, bone cement; double asterisk **, dural sac; triple asterisk ***, cephalic). 
Karnofsky score, and ECOG postoperative 3 months were collected.

\section{Surgical Techniques and Illustrative Cases}

All surgeries were performed by an experienced spinal tumor surgeon under general anesthesia. The indication for transfusion was HGB less than $80 \mathrm{~g} / \mathrm{L}$ or less than 90 $\mathrm{g} / \mathrm{L}$ for coronary disease patients.

Minimally invasive tubular surgery was performed through an expandable tubular retractor system via a trans muscular approach. Laminectomy and corpectomy were performed by piecemeal excision. The structure, such as spinous processes, lamina, facet joint on the other side, and muscle tissue, were protected. (Figure 2). The pedicle projection of lesion segments and 1-2 upper and lower vertebra levels was identified under fluoroscopy and marked in the skin. Pedicle screws were percutaneously placed under fluoroscopy 1-2 levels above and below the lesion segments. A $4 \mathrm{~cm}$ skin incision was made $2 \mathrm{~cm}$ or more lateral from the lesion pedicle's skin projection, depending on the degree of obesity. The deep fascia was cut longitudinal, and the muscle space between the longissimus and the multifidus parts of the sacrospinalis muscle was bluntly separated, and a K-wire was used to locate the pedicle. We placed the tubular retractor with the help of the guidance of K-wire. Then, properly peel off the multifidus part of the sacrospinalis muscle to expose the lesion vertebra's transverse process and facet joints. The residual transverse process, facet, and lamina were removed in blocks to the dural sac and tumor exposure. Spatula and osteotome were used to carefully remove the pedicle tumor, the vertebral body, and the tumor protruding into the vertebral canal behind the vertebral body by piecemeal excision. The nerve root should be exposed and protected. Bone cement was used to fill and strengthen the remaining vertebral body and adjacent vertebral body lesions.

Conventional surgery was performed via the median posterior approach. The deep fascia was cut longitudinal along the incision. Sacrospinalis muscles were stripped from the bone surface to expose the lamina and facet joints to 2 levels of the upper and lower vertebra (Figure 3). Pedicle screws were inserted on 2 levels of the upper and lower vertebra. The transverse process, facet, and lamina
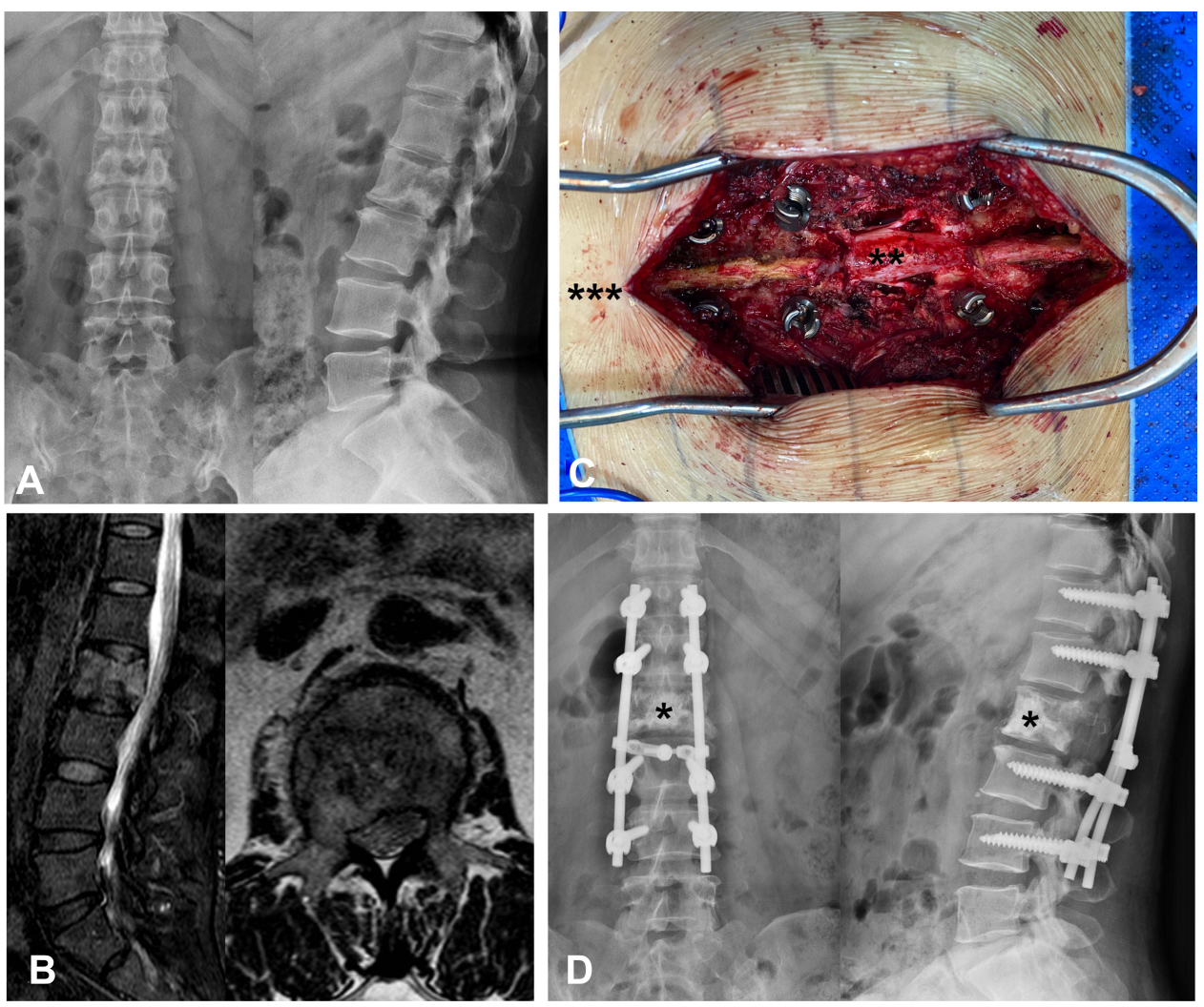

Figure 3 Illustration of conventional surgery. (A) Preoperative X-ray showing bone destruction of L2 vertebra. (B) Preoperative MRI showing metastatic epidural spinal cord compression due to collapsed L2 metastatic lesion. (C) conventional open decompression was performed through a posterior central incision. (D) Postoperative X-ray showing the implants. (asterisk *, bone cement; double asterisk **, dural sac; triple asterisk ***, cephalic). 
Table I Baseline Characteristics Comparing Between MiniInvasive (M) and Conventional (C) Groups

\begin{tabular}{|c|c|c|c|}
\hline Characteristics & $M(n=14)$ & $C(n=22)$ & $P$ \\
\hline \multicolumn{4}{|l|}{ Gender } \\
\hline Female & 5 & 9 & 0.755 \\
\hline Male & 9 & 13 & \\
\hline Age & $67 \pm 3$ & $65 \pm 2$ & 0.603 \\
\hline BMI & $23 \pm 1$ & $24 \pm 1$ & 0.410 \\
\hline \multicolumn{4}{|l|}{ ASA score } \\
\hline 1 & 0 & 1 & 0.089 \\
\hline II & 10 & 8 & \\
\hline III & 4 & 13 & \\
\hline \multicolumn{4}{|l|}{ Tumor pathology } \\
\hline Renal & 3 & 4 & 0.551 \\
\hline Lung & 4 & 4 & \\
\hline Prostate & 2 & 3 & \\
\hline Hematological malignancy & 3 & 3 & \\
\hline Uroepithelium & 1 & 1 & \\
\hline Digestive tract malignancy & 1 & I & \\
\hline Hepatobiliary malignancy & 0 & 2 & \\
\hline Breast & 0 & 3 & \\
\hline Gynecological malignancy & 0 & 1 & \\
\hline \multicolumn{4}{|l|}{ Blood supply } \\
\hline Hypervascular (renal, Hepatobiliary) & 3 & 6 & 0.908 \\
\hline Non-hyper vascular (lung, etc.) & 11 & 16 & \\
\hline \multicolumn{4}{|l|}{ Compression grade (Bilsky) } \\
\hline 1 & 2 & 2 & 0.711 \\
\hline 2 & 8 & 12 & \\
\hline \multicolumn{4}{|l|}{ Location of the lesion } \\
\hline Lumbar spine & 8 & 15 & 0.501 \\
\hline Thoracic spine & 6 & 7 & \\
\hline Tokuhashi score & $7.6 \pm 0.6$ & $9.0 \pm 0.4$ & 0.056 \\
\hline SINS score & $10.4 \pm 0.3$ & $8.6 \pm 0.4$ & 0.002 \\
\hline \multicolumn{4}{|l|}{ Ambulatory status } \\
\hline Nonambulatory & 3 & 7 & 0.706 \\
\hline Ambulatory & 11 & 15 & \\
\hline \multicolumn{4}{|l|}{ AIS } \\
\hline D & 2 & 2 & 0.711 \\
\hline $\mathrm{E}$ & 8 & 12 & \\
\hline VAS & $7.8 \pm 0.1$ & $7.8 \pm 0.1$ & 0.698 \\
\hline Karnofsky score & $59 \pm 2$ & $56 \pm 1$ & 0.181 \\
\hline ECOG score & $2.3 \pm 0.2$ & $2.1 \pm 0.1$ & 0.357 \\
\hline HGB (g/L) & $120 \pm 6$ & $129 \pm 4$ & 0.193 \\
\hline Hct (\%) & $36.1 \pm 1.9$ & $38.9 \pm 1.2$ & 0.213 \\
\hline Alb $(g / L)$ & $38.0 \pm 1.3$ & $41.5 \pm 0.9$ & 0.026 \\
\hline
\end{tabular}

Notes: NO Compression grade (Bilsky) and AIS were assigned for patients with decompression segment lower than $L 3$. Bold font, $P<0.05$.

Abbreviations: SINS, spinal instability neoplastic score; ASA, American Society of Anesthesiologists; BMI, body mass index; AIS, American Spinal Injury Association Impairment Scale; ECOG, Eastern Cooperative Oncology Group; HGB, haemoglobin; Hct, haematocrit; Alb, albumin; VAS, visual analogue scale. were removed by piecemeal excision to the dural sac and tumor exposure. Spatula and osteotome were used to carefully remove the pedicle tumor, the vertebral body, and the tumor protruding into the vertebral canal behind the vertebral body by piecemeal excision. The nerve root should be exposed and protected. Bone cement was used to fill and strengthen the remaining vertebral body lesions.

\section{Statistical Analysis}

Continuous variables were presented as mean (standard \pm deviation). $T$-test was used to detect the difference among continuous variables. The differences among the categorical variables between different groups were analyzed using the chi-square test. All tests were 2-sides. Delete cases with missing values during the statistical process. A p-value $<0.05$ was considered statistically significant. All statistical analyses were performed with the IBM SPSS Statistics 25 (IBM Corporation, Armonk, NY.).

\section{Results}

The detailed characteristics were shown in Table 1. Except for SINS and preoperative Alb, there were no significant differences in the demographic, preoperative tumor-related data, functional status, and laboratory data between $\mathrm{M}$ and $\mathrm{C}$ groups. M group had higher SINS (10.4 vs 8.6, $\mathrm{p}=0.002$ ) and lower preoperative Alb (38.0 vs 41.5, $\mathrm{p}=0.026$ ) than the $\mathrm{C}$ group.

The surgical outcomes were shown in Table 2. There were no significant differences in the incidence of preoperative arterial embolism, blood transfusion, and complications between the $\mathrm{M}$ and $\mathrm{C}$ groups. Operative time was comparable in the two groups. The amount of blood transfusion in group $\mathrm{C}$ was almost twice as much as that in group $\mathrm{M}$, although without statistical significance (429 vs $764 \mathrm{~mL}, \mathrm{p}=0.071)$. M group had less blood loss (718 vs $1275 \mathrm{~mL}, \mathrm{p}=0.045$ ), the amount of postoperative drainage (first day: 57 vs $275 \mathrm{~mL}, \mathrm{p}<0.001$; total: 141 vs $874 \mathrm{~mL}$, $\mathrm{p}<$ 0.001 ) and the time of drainage (3.1 vs 7.0 days, $\mathrm{p}<$ 0.001). Postoperative hospitalization in group $M$ was shorter than that in group $\mathrm{C}$ ( 8.8 vs 11.3 days, $\mathrm{p}<0.001)$.

We conducted a sub-analysis to clarify the relevance of the tumor's vascular supply to this mini-invasive technique (Table 3). For patients with hyper-vascular tumor (renal cell cancer), the amount of postoperative drainage (first day: 32 vs $244 \mathrm{~mL}, \mathrm{p}<0.001$; total: 152 vs $888 \mathrm{~mL}, \mathrm{p}<0.001)$ and the time of drainage ( 4.0 vs 7.5 days, $p<0.001)$ in group $M$ were 
Table 2 Operative Related Data Comparing Between MiniInvasive (M) and Conventional (C) Groups

\begin{tabular}{|c|c|c|c|}
\hline Characteristics & $M(n=14)$ & $C(n=22)$ & $P$ \\
\hline $\begin{array}{l}\text { Preoperative embolism } \\
\text { Yes } \\
\text { No }\end{array}$ & $\begin{array}{l}2 \\
12\end{array}$ & $\begin{array}{l}2 \\
20\end{array}$ & 0.634 \\
\hline Operative time & $243 \pm 13$ & $247 \pm 11$ & 0.822 \\
\hline $\begin{array}{l}\text { Complications } \\
\text { Urinary infection } \\
\text { Dural tear } \\
\text { Screw displacement }\end{array}$ & $\begin{array}{l}0 \\
2 \\
1\end{array}$ & $\begin{array}{l}\mathrm{I} \\
\mathrm{I} \\
0\end{array}$ & $\begin{array}{l}0.418 \\
0.547 \\
0.389\end{array}$ \\
\hline Blood loss (mL) & $718 \pm 198$ & $1275 \pm 172$ & 0.045 \\
\hline $\begin{array}{l}\text { Blood transfusion (patients) } \\
\text { Yes } \\
\text { No }\end{array}$ & $\begin{array}{l}10 \\
4\end{array}$ & $\begin{array}{l}19 \\
3\end{array}$ & 0.394 \\
\hline $\begin{array}{l}\text { Blood transfusion }(\mathrm{mL}) \\
\text { Intraoperative } \\
\text { Within } 3 \text { days post } \\
\text { operation }\end{array}$ & $\begin{array}{l}429 \pm 98 \\
429 \pm 98\end{array}$ & $\begin{array}{l}691 \pm 106 \\
764 \pm 129\end{array}$ & $\begin{array}{l}0.098 \\
0.071\end{array}$ \\
\hline $\begin{array}{l}\text { Drainage } \\
\text { First day }(\mathrm{mL}) \\
\text { Total amount }(\mathrm{mL}) \\
\text { Time (day) }\end{array}$ & $\begin{array}{l}57 \pm 10 \\
14 \mid \pm 32 \\
3.1 \pm 0.2\end{array}$ & $\begin{array}{l}275 \pm 18 \\
873 \pm 56 \\
7.0 \pm 0.4\end{array}$ & $\begin{array}{l}<0.001 \\
<0.001 \\
<0.001\end{array}$ \\
\hline $\begin{array}{l}\text { Postoperative } \\
\text { hospitalization (day) }\end{array}$ & $8.8 \pm 1.0$ & $1 \mathrm{I} .3 \pm 0.7$ & 0.029 \\
\hline
\end{tabular}

Note: Bold font, $P<0.05$.

less than that in group C. Other index including operative time, blood loss et al were comparable between two groups. However, patients in group $\mathrm{M}$ need less blood transfusion, although without statistical significance $(667$ vs $1000 \mathrm{~mL}, \mathrm{p}<$ $0.05)$. For patients with hypo-vascular tumor, in addition to the amount of drainage (first day: 66 vs $294 \mathrm{~mL}, \mathrm{p}<0.001$; total: 137 vs $824 \mathrm{~mL}, \mathrm{p}<0.001)$, and the time of drainage $(2.8$ vs 6.4 days, $\mathrm{p}<0.001$ ), $\mathrm{M}$ group also had less blood loss (395 vs $1219 \mathrm{~mL}, \mathrm{p}<0.001$ ), and blood transfusion (364 vs $700 \mathrm{~mL}, \mathrm{p}<0.05)$ compared with that in group C. In the M group, patients with hypo-vascular tumors had less blood loss (395 vs $1900 \mathrm{~mL}, \mathrm{p}<0.001$ ) than $\mathrm{C}$ group. The amount of blood transfusion was less in group $\mathrm{M}$ although without statistical significance (346 vs $667 \mathrm{~mL}, \mathrm{p}<0.05$ ).

Postoperative day 1 and day 3 parameters, including HGB, Hct, and Alb, were shown in Figure 4. All parameters were significantly declined compared with preoperative and maintained a relatively stable level within 3 days post-operation. There were no significant differences in HGB, Hct, and Alb between the two groups at postoperative day 1 and day 3. However, HGB, Hct, and Alb declined more in group $\mathrm{C}$.

There were no significant differences in functional improvement of ambulatory status and AIS between the two groups. Postoperative VAS was significantly improved than preoperative in both groups and maintained at a stable level at 3 months post-operation. Karnofsky and ECOG score at 3 months post-operation was a significant improvement compared with preoperative in both groups. There were no significant differences in Karnofsky score and ECOG at 3 months post-operation between the two groups. Group M had less VAS compared to group C (2.3 vs 2.7, $\mathrm{p}<0.015$ ). (Figures 4 and 5).

\section{Discussion}

Minimally invasive tubular surgery is an emerging technique applied in the treatment of patients with spinal metastasis. Previous studies reported that metastatic spine tumors could be safely resected through a tubular retractor with even less tissue destruction and quicker functional recovery than mini-open and conventional surgery. The present study provides a more comprehensive analysis to evaluate this technique's perioperative safety and efficacy for patients with thoracolumbar metastasis and guide surgeons to select the best candidates.

In this study, both groups' VAS, Karnofsky score, and ECOG were significantly improved after surgery, and postoperative functional recovery was comparable. HGB, Hct, and Alb were significantly declined post-operation in the two groups. We attempted to compare the change of HGB, Hct, and Alb in two groups that may reflect the degree of surgical trauma. The results showed that Alb decreased more significantly in group $\mathrm{C}$ post-operation. Similar to the previous study, ${ }^{15-19}$ tubular surgery had significantly less blood loss, fewer blood transfusions, minor drainage, and shorter postoperative hospitalization than conventional surgery. However, we found intraoperative cauterization was difficult for patients with hyper-vascular tumors, such as renal cell cancer. The hyper-vascular tumor usually bleeds until they are completely resected. This finding encouraged us to conduct a sub-analysis of our current data, and the result showed that compared with hypervascular tumors such as renal, patients with hypovascular tumors would benefit more from tubular surgery. This result was different from mini-open surgery and was mainly due to the limited vision under the tubular. ${ }^{7,9}$ Compared with mini-open surgery, tubular surgery had 
Table 3 Sub-Analysis of Operative Related Data

\begin{tabular}{|c|c|c|c|c|c|c|}
\hline \multirow[t]{2}{*}{ Characteristics } & \multicolumn{2}{|c|}{$\begin{array}{l}\text { Hyper-Vascular Tumor } \\
\text { (Renal Cell Cancer) }\end{array}$} & \multicolumn{2}{|c|}{ Hypo-Vascular Tumor } & \multicolumn{2}{|c|}{ Minimally Invasive Tubular Surgery } \\
\hline & $M(n=3)$ & $C(n=4)$ & $M(n=I I)$ & $C(n=16)$ & $\begin{array}{l}\text { Hypo-Vascular } \\
(n=I I)\end{array}$ & $\begin{array}{l}\text { Hyper-Vascular } \\
(n=3)\end{array}$ \\
\hline $\begin{array}{l}\text { Operation time } \\
\text { Blood loss }(\mathrm{mL})\end{array}$ & $\begin{array}{l}283 \pm 34 \\
1900 \\
\pm 458\end{array}$ & $\begin{array}{l}260 \pm 42 \\
1613 \pm 652\end{array}$ & $\begin{array}{l}232 \pm 13 \\
395 \pm 71\end{array}$ & $\begin{array}{l}240 \pm 12 \\
1219 \\
\pm 175 * *\end{array}$ & $\begin{array}{l}232 \pm 13 \\
395 \pm 71\end{array}$ & $\begin{array}{l}283 \pm 34 \\
1900 \pm 458 * *\end{array}$ \\
\hline \multicolumn{7}{|l|}{ Blood transfusion $(\mathrm{mL})$} \\
\hline $\begin{array}{l}\text { Intraoperative } \\
\text { Within } 3 \text { days post operation }\end{array}$ & $\begin{array}{l}667 \pm 353 \\
667 \pm 353\end{array}$ & $\begin{array}{l}800 \pm 163 \\
1000 \pm 346\end{array}$ & $\begin{array}{l}364 \pm 85 \\
364 \pm 85\end{array}$ & $\begin{array}{l}675 \pm 130 \\
700 \pm 139 *\end{array}$ & $\begin{array}{l}364 \pm 85 \\
364 \pm 85\end{array}$ & $\begin{array}{l}667 \pm 353 \\
667 \pm 353\end{array}$ \\
\hline \multicolumn{7}{|l|}{ Drainage } \\
\hline $\begin{array}{l}\text { First day }(\mathrm{mL}) \\
\text { Total amount }(\mathrm{mL}) \\
\text { Time (day) } \\
\text { Postoperative hospitalization } \\
\text { (day) }\end{array}$ & $\begin{array}{l}32 \pm 9 \\
|52 \pm 6| \\
4.0 \pm 0.6 \\
9.0 \pm 1.5\end{array}$ & $\begin{array}{l}244 \pm 29 * * \\
888 \pm|2| * * \\
7.5 \pm 0.5 * * \\
\mid 3.3 \pm 1.9\end{array}$ & $\begin{array}{l}66 \pm 12 \\
137 \pm 40 \\
2.8 \pm 0.2 \\
8.7 \pm 1.2\end{array}$ & $\begin{array}{l}294 \pm 18 * * \\
824 \pm 69 * * \\
6.4 \pm 0.5 * * \\
10.8 \pm 0.7\end{array}$ & $\begin{array}{l}66 \pm 12 \\
137 \pm 40 \\
2.8 \pm 0.2 \\
8.7 \pm 1.2\end{array}$ & $\begin{array}{l}32 \pm 9 \\
|52 \pm 6| \\
4.0 \pm 0.6 \\
9.0 \pm 1.5\end{array}$ \\
\hline
\end{tabular}

Notes: $* P<0.05$ (bold font); ${ }^{* * P<0.001 ~(b o l d ~ f o n t) . ~}$

stricter criteria on tumor type. For patients with hyper- recovery of tubular surgery, preoperative arterial embolism vascular tumors, the mini-open technique should be given or other intervention may be performed to control the priority. However, considering the advantages of more fast bleeding during operation for patients with hyper-

HGB (g/L)

$\left(p^{\mathrm{a} 1}=0.024 ; \mathrm{p}^{\mathrm{b} 1}=0.025 ; \mathrm{p}^{\mathrm{c} 1}=0.443\right.$;

$\mathrm{p}^{\mathrm{d} 1}<0.001 ; \mathrm{p}^{\mathrm{e} 1}<0.001 ; \mathrm{p}^{\mathrm{f1}}=0.358$ )

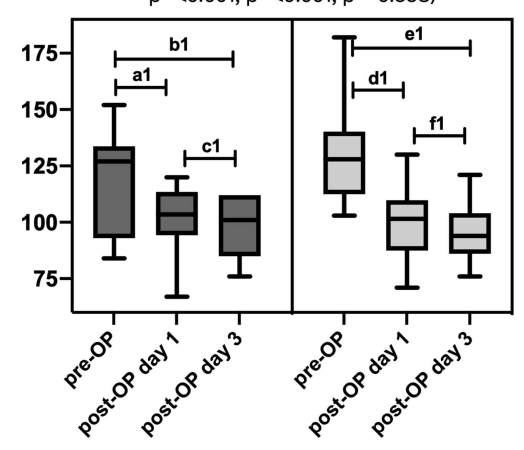

VAS

$\left(\mathrm{p}^{\mathrm{a} 4}<0.001 ; \mathrm{p}^{\mathrm{b4}}<0.001 ; \mathrm{p}^{\mathrm{c4}}=0.259\right.$

$\left.\mathrm{p}^{\mathrm{d4}}<0.001 ; \mathrm{p}^{\mathrm{e}}<0.001 ; \mathrm{p}^{\mathrm{f4}}=0.227\right)$

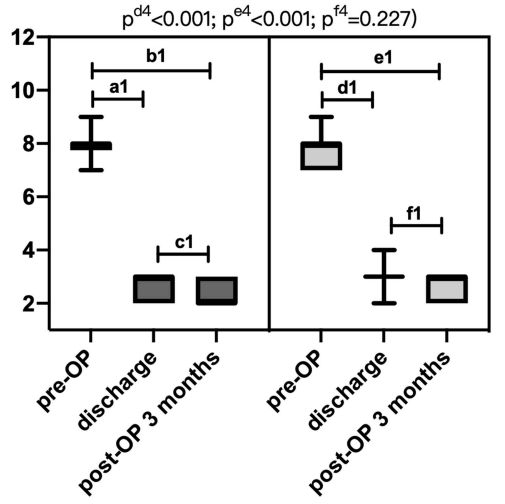

Hct (\%)
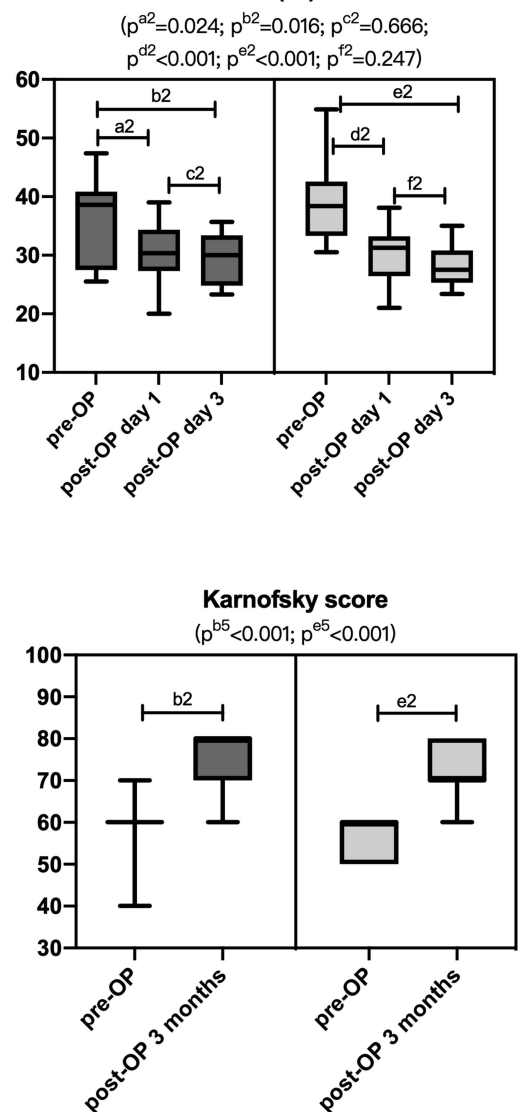

Alb (g/L)

$\left(p^{\mathrm{a} 3}<0.001 ; \mathrm{p}^{\mathrm{b} 3}=0.001 ; \mathrm{p}^{\mathrm{c} 3}=0.299 ;\right.$

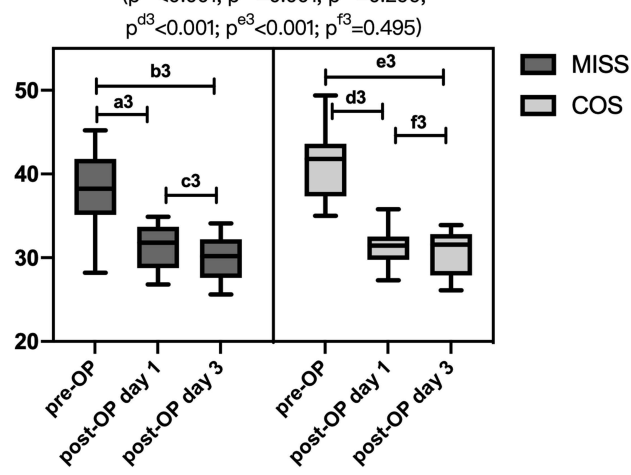

ECOG score

$\left(p^{b 6}=0.043 ; p^{e 6}<0.001\right)$

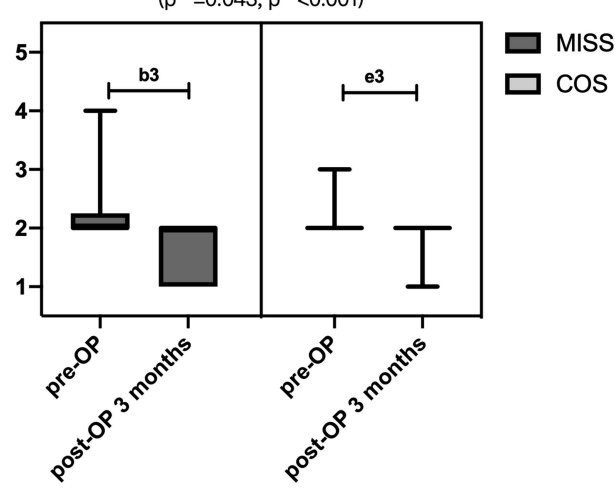

Figure 4 The perioperative HGB, Hct, Alb, VAS, Karnofsky, and ECOG scores of patients in mini-invasive and conventional groups. (Box and whiskers: min to max). 
Ambulatory status $(p=0.062)$

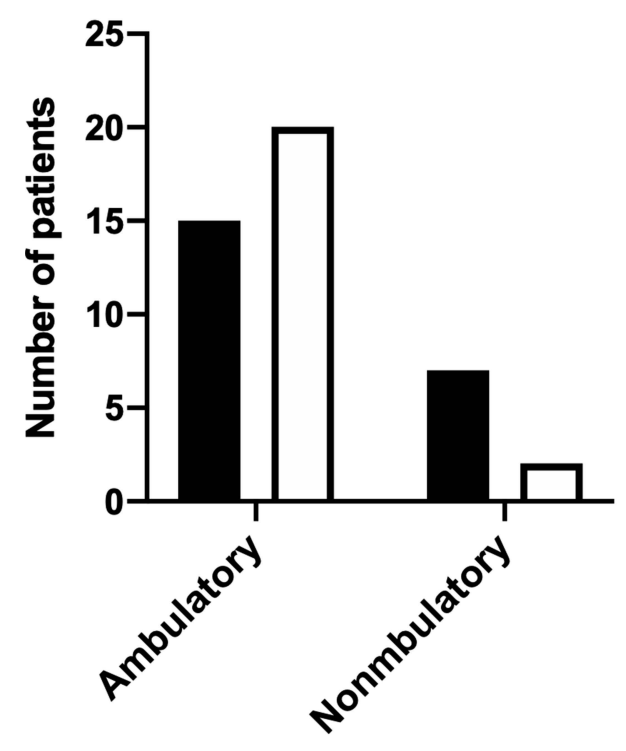

Ambulatory status $(p=0.067)$

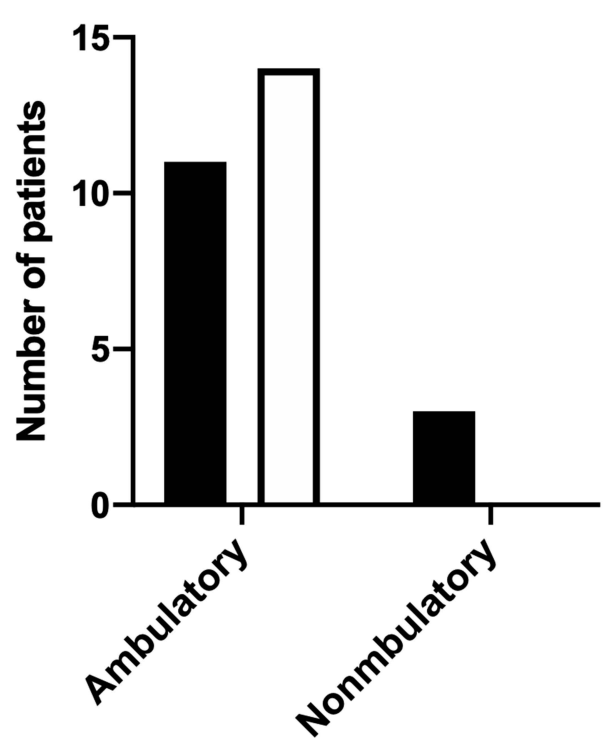

AIS $(p=0.541)$

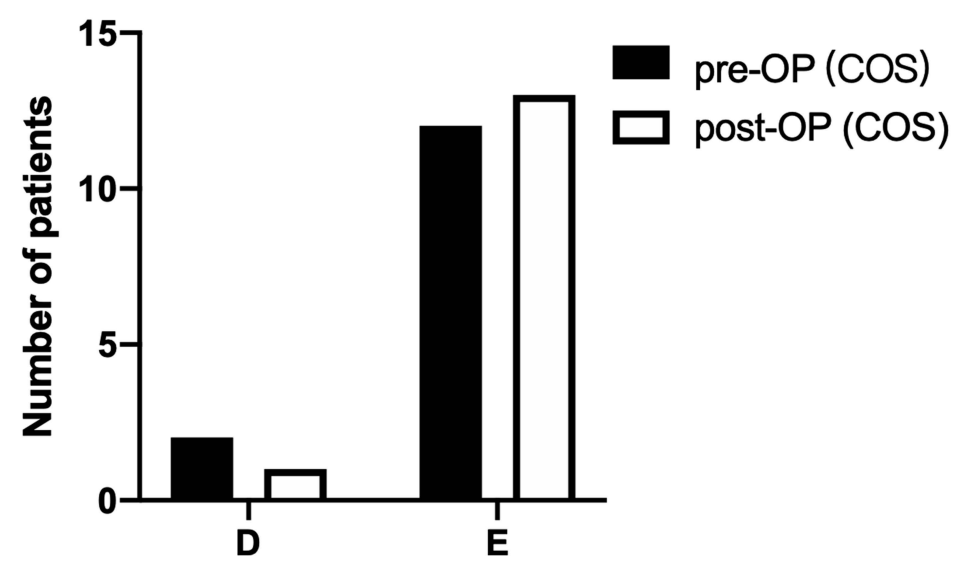

AIS $(p=0.541)$

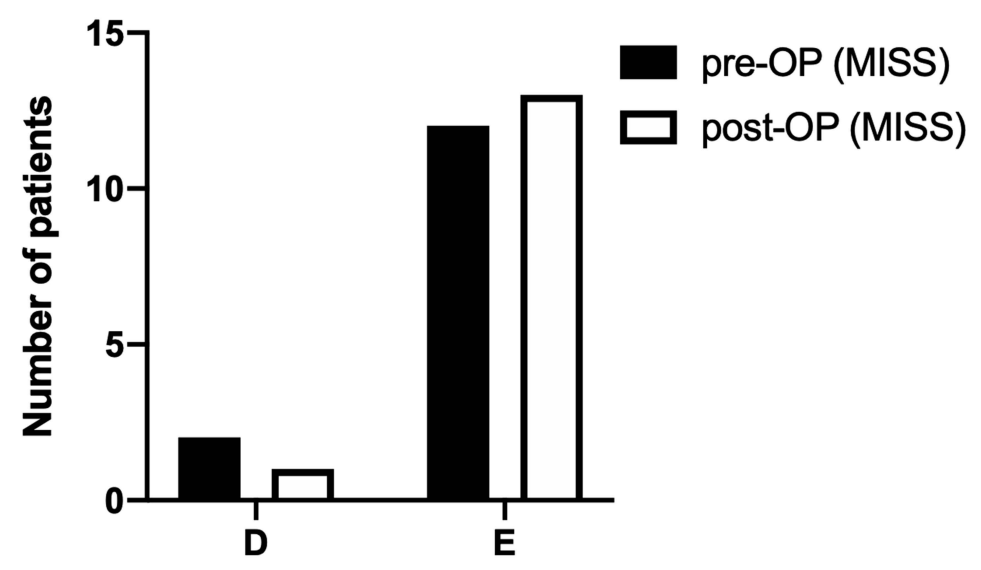

Figure 5 The pre and post-operative Ambulatory status and AIS of MISS and COS group of patients in mini-invasive and conventional groups. (Box and whiskers: min to $\max )$.

vascular tumors. Although preoperative arterial embolism had been proven to reduce blood loss in conventional surgery, its role in tubular surgery remains confirmed by further studies.

The incidence of surgical complications for conventional surgery is higher in patients with symptomatic spinal metastases. Surgical trauma and perioperative complications often affect the continuity of subsequent treatment. ${ }^{5}$ All minimally invasive spine surgeries are characterized by minor physiological insult and early mobilization, and rapid recovery. Our results suggested that patients who underwent tubular surgery recover faster than patients who underwent conventional surgery. They would have more opportunities to receive adjuvant therapy such as radiotherapy at early stage postoperative, which played an essential role in the local tumor control. ${ }^{22}$ Regrettably, our study showed tubular surgery had no significant advantage on operation time compared with 
conventional surgery. Besides, the operation time and complication rate were relatively higher than the previous study performed by ${ }^{19}$ and Nzokou et al. ${ }^{17}$ The complications of the tubular surgery were mainly dural tears. The learning curve for utilizing an emerging technique must be taken into account when performing such a surgical strategy. The previous study focused on the learning curve of Mis TLIF and suggested that decompression through a tubular retractor was a higher technical requirement with a relatively long operation time and more complications at the early stage. Silva et al analyzed 150 patients with degenerative lumbar disease who underwent MITLIF. The most frequent complication was a dural tear (5.32\%), and the complication rates were $33 \%$ and $20.51 \%$ for $50 \%$ and $90 \%$ learning milestones, respectively. They reported that $90 \%$ of the learning curve would be achieved around the 40th case. ${ }^{23}$ The operation time and complication rate will improve with the growth of this technique's learning curve in the future.

Because of the poor holding power of the screws for patients with spinal metastasis and osteoporosis, patients with spinal metastasis usually received long-level fusion. In the present study, all patients (22 patients) in the conventional group underwent 4-level fusion. On the other side, Short-segment fixation, not including the decompressed segment, was used at the initial stage in minimally invasive tubular surgery. Due to limited exposure, the transverse connection could not be applied, and 1 patient appeared in pedicle screw displacement. In order to avoid the occurrence of internal fixation failure, Harel et $\mathrm{al}^{15}$ and Zirai et $\mathrm{al}^{16}$ recommended extending the internal fixation segment or applying the cement screw technique. Besides, Harel et $\mathrm{al}^{15}$ suggested screws should be placed on the healthy side of the decompressed segment to convert the bridge structure into a classic three-point fixation, thereby increasing the holding power of the screws and overall stability. There were potential pitfalls in using such a large posterior construct (4-level fusion), especially lumbar stiffness and adjacent segment degeneration. Adjacent segment degeneration was a late complication after spinal fusion surgery. Lumbar stiffness and adjacent segment degeneration were more concerned in patients with benign spinal diseases. Previously studies showed that lumbar stiffness $^{24,25}$ and the rate of adjacent segment degeneration ${ }^{26,27}$ were positively related to the length of fusion. As the prognosis of patients was getting better, the survival time of patients with spinal metastasis was prolonged. The surgeon should pay more attention to the pitfalls of long-level fusion, such as adjacent segment degeneration and lumbar stiffness.

There are limitations to the present study. First, it was limited by its retrospective and non-randomized nature, and there would be a particular bias in patient selection. To minimize the selective bias, we strictly limited the screening criteria for patients' selection. Table 1 showed that there were no significant differences in the baseline characteristic between the two groups. Second, the relatively small sample size may affect the outcomes available for analysis. A large-scale, prospective, randomized study should be carried out to validate these results. However, this study provides important information regarding applying this technique to treat spinal metastasis. In addition, this technique's characters make itself more suitable for patients with multiple comorbidities who are at high risk of perioperative complications. ${ }^{5}$

\section{Conclusions}

In selected cases, minimally invasive tubular surgery is safe and effective for patients with spinal metastasis. Patients with hypo-vascular tumors were more suitable for this technique with less blood loss, fewer blood transfusions, minor drainage, and shorter postoperative hospitalization.

\section{Data Sharing Statement}

The datasets generated and/or analysed during the current study are not publicly available due privacy or ethical restrictions but are available from the corresponding author on reasonable request.

\section{Ethical Approval}

This retrospective study involving human participants was in accordance with the ethical standards of the institutional and national research committee and with the 1964 Helsinki Declaration and its later amendments or comparable ethical standards. The local Ethics Committee of Peking University First Hospital approved this study.

\section{Consent to Participate}

All participants in this study were above 16 years of age. The need for written informed consent was waived by the Peking University First Hospital ethics committee due to retrospective nature of the study.

\section{Author Contributions}

All authors contributed to data analysis, drafting or revising the article, gave final approval of the version to be 
published, agreed to the submitted journal, and agree to be accountable for all aspects of the work.

\section{Funding}

There is no funding to report.

\section{Disclosure}

The authors declare that they have no competing interests.

\section{References}

1. Siegel RL, Miller KD, Jemal A. Cancer statistics, 2019. CA Cancer J Clin. 2019;69(1):7-34. doi:10.3322/caac.21551

2. Spratt DE, Beeler WH, de Moraes FY, et al. An integrated multidisciplinary algorithm for the management of spinal metastases: an International Spine Oncology Consortium report. Lancet Oncol. 2017;18(12):e720-30. doi:10.1016/S1470-2045(17)30612-5

3. Patchell RA, Tibbs PA, Regine WF, et al. Direct decompressive surgical resection in the treatment of spinal cord compression caused by metastatic cancer: a randomised trial. Lancet. 2005;366 (9486):643-648. doi:10.1016/S0140-6736(05)66954-1

4. Jansson KA, Bauer HCF. Survival, complications and outcome in 282 patients operated for neurological deficit due to thoracic or lumbar spinal metastases. Eur Spine J. 2006;15(2):196-202. doi:10.1007/ s00586-004-0870-6

5. Finkelstein JA, Zaveri G, Wai E, Vidmar M, Kreder H, Chow E. A population-based study of surgery for spinal metastases. Survival rates and complications. $J$ Bone Joint Surg Br. 2003;85 (7):1045-1050. doi:10.1302/0301-620X.85B7.14201

6. Tian NF, Wu YS, Zhang XL, Xu HZ, Chi YL, Mao FM. Minimally invasive versus open transforaminal lumbar the current evidence. Eur Spine J. 2013;22:1741-1749. doi:10.1007/s00586-013-2747-z

7. Miscusi M, Polli FM, Forcato S, et al. Comparison of minimally invasive surgery with standard open surgery for vertebral thoracic metastases causing acute myelopathy in patients with short- or mid-term life expectancy: surgical technique and early clinical results. J Neurosurg Spine. 2015;22(5):518-525. doi:10.3171/ 2014.10.SPINE131201

8. Fang T, Dong J, Zhou X, McGuire RA, Li X. Comparison of mini-open anterior corpectomy and posterior total en bloc spondylectomy for solitary metastases of the thoracolumbar spine clinical article. J Neurosurg Spine. 2012;17(4):271-279. doi:10.3171/2012.7. SPINE111086

9. Hansen-Algenstaedt N, Kwan MK, Algenstaedt P, et al. Comparison between minimally invasive surgery and conventional open surgery for patients with spinal metastasis: a prospective propensity score-matched study. Spine (Phila Pa 1976). 2017;42(10):789-797. doi:10.1097/BRS.0000000000001893

10. Hikata T, Isogai N, Shiono Y, et al. A retrospective cohort study comparing the safety and efficacy of minimally invasive versus open surgical techniques in the treatment of spinal metastases. Clin Spine Surg. 2017;30(8):E1082-7. doi:10.1097/BSD.0000000000000460

11. Huang TJ, Hsu RWW, Li YY, Cheng CC. Minimal access spinal surgery (MASS) in treating thoracic spine metastasis. Spine (Phila Pa 1976). 2006;31(16):1860-1863. doi:10.1097/01. brs.0000225995.56028.46

12. Kumar N, Malhotra R, Maharajan K, et al. Metastatic spine tumor surgery a comparative study of minimally invasive approach using percutaneous pedicle screws fixation versus open approach. Clin Spine Surg. 2017;30:E1015-21. doi:10.1097/BSD.00000000 00000400
13. Lau D, Chou D. Posterior thoracic corpectomy with cage reconstruction for metastatic spinal tumors: comparing the mini-open approach to the open approach. $J$ Neurosurg Spine. 2015;23(2):217-227. doi:10.3171/2014.12.SPINE14543

14. Holly LT, Schwender JD, Rouben DP, Foley KT. Minimally invasive transforaminal lumbar interbody fusion: indications, technique and complications. Neurosurg Focus. 2006;20(3):1-5.

15. Harel R, Doron O, Knoller N. Minimally invasive spine metastatic tumor resection and stabilization: new technology yield improved outcome. Biomed Res Int. 2015;2015. doi:10.1155/2015/948373

16. Zairi F, Arikat A, Allaoui M, Marinho P, Assaker R. Minimally invasive decompression and stabilization for the management of thoracolumbar spine metastasis: clinical article. J Neurosurg Spine. 2012;17(1):19-23. doi:10.3171/2012.4.SPINE111108

17. Nzokou A, Weil AG, Shedid D. Minimally invasive removal of thoracic and lumbar spinal tumors using a nonexpandable tubular retractor: clinical article. J Neurosurg Spine. 2013;19(6):708-715. doi:10.3171/2013.9.SPINE121061

18. Deutsch H, Boco T, Lobel J. Minimally invasive transpedicular vertebrectomy for metastatic disease to the thoracic spine. J Spinal Disord Tech. 2008;21(2):101-105. doi:10.1097/ BSD.0b013e31805fea01

19. Schwab JH, Gasbarrini A, Cappuccio M, et al. Minimally invasive posterior stabilization improved ambulation and pain scores in patients with plasmacytomas and/or metastases of the spine. Int J Surg Oncol. 2011;2011:1-5. doi:10.1155/2011/239230

20. Kato S, Hozumi T, Takaki Y, Yamakawa K, Goto T, Kondo T. Optimal schedule of preoperative embolization for spinal metastasis surgery. Spine (Phila Pa 1976). 2013;38(22):1964-1969. doi:10.1097/BRS.0b013e3182a46576

21. Hong CG, Cho JH, Suh DC, Hwang CJ, Lee DH, Lee CS. Preoperative embolization in patients with metastatic spinal cord compression: mandatory or optional? World J Surg Oncol. 2017;15 (1):45. doi:10.1186/s12957-017-1118-3

22. Sandhu N, Benson KRK, Kumar KA, et al. Local control and toxicity outcomes of stereotactic radiosurgery for spinal metastases of gastrointestinal origin. J Neurosurg Spine. 2020;33(1):87-94. doi:10.3171/ 2020.1.SPINE191260

23. Silva PS, Pereira P, Monteiro P, Silva PA, Vaz R. Learning curve and complications of minimally invasive transforaminal lumbar interbody fusion. Neurosurg Focus. 2013;35(2):E7. doi:10.3171/2013.5. FOCUS13157

24. Kimura H, Fujibayashi S, Otsuki B, Takahashi Y, Nakayama T, Matsuda S. Effects of lumbar stiffness after lumbar fusion surgery on activities of daily living. Spine (Phila Pa 1976). 2016;41 (8):719-727. doi:10.1097/BRS.0000000000001300

25. Zhang X, Yuan L, Zeng Y, Liu Y, Chen Z, Li W. Evaluation of lumbar stiffness after long-level fusion for degenerative lumbar scoliosis via a Chinese version of the lumbar stiffness disability index. Spine J. 2021:S1529-9430(21)00781-6. doi:10.1016/j. spinee.2021.06.017

26. Yang JY, Lee JK, Song HS. The impact of adjacent segment degeneration on the clinical outcome after lumbar spinal fusion. Spine (Phila Pa 1976). 2008;33(5):503-507. doi:10.1097/BRS.0b013e $3181657 \mathrm{dc} 3$

27. Cheh G, Bridwell KH, Lenke LG, et al. Adjacent segment disease following lumbar/thoracolumbar fusion with pedicle screw instrumentation: a minimum 5-year follow-up. Spine (Phila Pa 1976). 2007;32(20):2253-2257. doi:10.1097/BRS.0b013e31814b2d8e 


\section{Publish your work in this journal}

Cancer Management and Research is an international, peer-reviewed open access journal focusing on cancer research and the optimal use of preventative and integrated treatment interventions to achieve improved outcomes, enhanced survival and quality of life for the cancer patient.

The manuscript management system is completely online and includes a very quick and fair peer-review system, which is all easy to use. Visit http://www.dovepress.com/testimonials.php to read real quotes from published authors. 